\title{
Erratum to: Conchomeatoplasty: a new technique
}

\author{
Vittorio Giacomarra $\cdot$ Giacomo Spinato $\cdot$ \\ Federica Bullo • Maria Cristina Da Mosto • \\ Paolo Boscolo-Rizzo • Giancarlo Tirelli
}

Published online: 14 August 2013

(c) Springer-Verlag Berlin Heidelberg 2013

\section{Erratum to: Eur Arch Otorhinolaryngol}

\section{DOI 10.1007/s00405-013-2625-7}

The author would like to correct his misspelled name in the original version of the published article. The correct name should be "Giancarlo Tirelli".

The online version of the original article can be found under doi:10.1007/s00405-013-2625-7.

V. Giacomarra

ENT Clinic, Department of Surgery, Hospital of Tolmezzo,

Tolmezzo, Italy

G. Spinato $\cdot$ F. Bullo $\cdot$ G. Tirelli

ENT Clinic, Head and Neck Department, Hospital of Cattinara,

University of Trieste, Trieste, Italy

M. C. Da Mosto · P. Boscolo-Rizzo ( $\square)$

ENT Clinic, Department of Neurosciences, Treviso Regional

Hospital, University of Padua, 31100 Treviso, Italy

e-mail: paolo.boscolorizzo@unipd.it 